\title{
研究
}

\section{Dissolution Behavior of SUS304 Stainless Steel due to General Corrosion in $\mathrm{H}_{2} \mathrm{SO}_{4}-\mathrm{NaCl}$ Aqueous Solution}

\author{
Satoshi Sunada, Kazuhiko Majima and Takeshi Matsuda \\ Department of Materials Systems Engineering and Life Science, Faculty of Engineering, Toyama University, \\ 3190 Gofuku, Toyama 930-8555.
}

Received March 11, 2005

\section{SYNOPSIS}

In this experiment, three kinds of sintered SUS304 stainless steels (P/M stainless steels) whose porosity ratios were 17.06 (compressed at $392 \mathrm{MPa}$ ), 11.78 (compressed at $588 \mathrm{MPa}$ ) and $8.75 \%$ (compressed at $784 \mathrm{MPa}$ ) were used. The dissolution behavior of these sintered SUS304 stainless steels in the aqueous solution composed of $\mathrm{H}_{2} \mathrm{SO}_{4}$ and $\mathrm{NaCl}$ were examined compared with that of the conventionally processed SUS304 stainless steel (I/M specimen). All of the P/M SUS304 specimens showed almost linear increment of corrosion mass loss against reaction time and the specimen with higher porosity ratio showed more mass loss, while the $\mathrm{I} / \mathrm{M}$ specimen showed evidently much less mass loss than any P/M specimens. The reactivation ratio for the P/M SUS304 specimen was higher than the I/M SUS304 specimen and it increased almost linearly with increasing porosity ratio. In the case of $72 \mathrm{ks}$ of reaction time, the charge transfer resistance, Rct, is highest in the specimen compressed at $785 \mathrm{MPa}$, while it is lowest in the P/M specimen compressed at $392 \mathrm{MPa}$. In the longer region than $144 \mathrm{ks}$, all of the three P/M specimens show the almost constant Rct value of $200 \Omega$. These Rct tendencies well correspond to the time dependence curve of mass loss.

KEY WORDS

sintered SUS304 stainless steel, mass loss, dissolution behavior, porosity ratio, electrochemical measurement, impedance measurement

\section{Introduction}

The discovery and development of austenitic stainless steel dates back to the first decades of $20^{\text {th }}$ century. Since then these alloys have been well known for their passivity and excellent corrosion resistance. SUS304, a representative austenitic stainless steel, has been applied in variety of industries, and the author has reported on the corrosion behavior of SUS304 stainless steel ${ }^{1-3)}$. However, the conventionally processed SUS304 stainless steel has poor machinability due to the low thermal conductivity and work hardening. Recently the sintered SUS304 stainless steel produced by powder metallurgy (P/M) process has been noted since $\mathrm{P} / \mathrm{M}$ process has the advantage of better formability to fabricate complex shape products without machining or welding. Many papers have been published on the mechanical properties of the SUS304 stainless steels produced by P/M process while there have been few on their corrosion properties from the view point of electrochemistry ${ }^{4}$.

The aim of the study is to clarify dissolution behaviors of sintered SUS304 stainless steel systematically using electrochemical procedure including impedance method and in this experiment, as the first stage, the effect of porosity ratio on dissolution behavior initiated by general corrosion was investigated by using sintered SUS304 stainless steel in comparison with the conventionally processed one.

\subsection{Experimental material}

\section{Experimental procedures}

Materials used for the experiment were SUS304 stainless steels: one was made by conventionally processed steel and the other was sintered one using powder metallurgy process. These compositions are shown in Table 1 and 2, respectively. Sintered materials were formed by 3 different compacting pressures. Conventionally processed SUS304, marked as I/M specimen in the text and figures, was sampled from the cast and wrought $2 \mathrm{~mm}$ thickness commercial plate, and a specimen of $12 \mathrm{~mm}$ in width and $60 \mathrm{~mm}$ in length was cut out of the plate. Sintered SUS304 was produced using water-atomized powder of approximately $60 \times 10^{-6} \mathrm{~m}$ in average diameter made by Daido Special Steel Co., Ltd. The appropriate amount of the powder was compressed to the size of $2.2 \times 12 \times 60$ in 
Table 1 Chemical composition (mass\%) of SUS304 stainless steel.

\begin{tabular}{c|c|c|c|c|c|c|c|c|c|c}
\hline \hline $\mathrm{C}$ & $\mathrm{Si}$ & $\mathrm{Mn}$ & $\mathrm{P}$ & $\mathrm{S}$ & $\mathrm{Ni}$ & $\mathrm{Cr}$ & $\mathrm{Mo}$ & $\mathrm{Cu}$ & $\mathrm{N}$ & $\mathrm{O}$ \\
\hline $\mathbf{0 . 0 6}$ & $\mathbf{0 . 4 3}$ & $\mathbf{1 . 1}$ & $\mathbf{0 . 0 3 3}$ & $\mathbf{0 . 0 0 3}$ & $\mathbf{8 . 5 2}$ & $\mathbf{1 8 . 3}$ & $\mathbf{0 . 1 1}$ & $\mathbf{0 . 2 9}$ & $\mathbf{0 . 0 4 9}$ & - \\
\hline \hline
\end{tabular}

I/M porosity ratio $\quad 0 \%$

Table 2 Chemical composition (mass\%) of SUS304 stainless steel powder.

\begin{tabular}{c|c|c|c|c|c|c|c|c|c|c}
\hline \hline $\mathrm{C}$ & $\mathrm{Si}$ & $\mathrm{Mn}$ & $\mathrm{P}$ & $\mathrm{S}$ & $\mathrm{Ni}$ & $\mathrm{Cr}$ & $\mathrm{Mo}$ & $\mathrm{Cu}$ & $\mathrm{N}$ & $\mathrm{O}$ \\
\hline $\mathbf{0 . 0 1 3}$ & $\mathbf{0 . 8 4}$ & $\mathbf{0 . 2 2}$ & $\mathbf{0 . 0 2 2}$ & $\mathbf{0 . 0 0 8}$ & $\mathbf{1 1 . 0 8}$ & $\mathbf{1 8 . 8 5}$ & $\mathbf{0 . 0 3}$ & $\mathbf{0 . 0 3}$ & $\mathbf{0 . 0 5}$ & $\mathbf{0 . 2 7}$ \\
\hline \hline
\end{tabular}

$\mathrm{P} / \mathrm{M}$ compacting pressure $392 \mathrm{MPa}\left(4 \mathrm{ton} / \mathrm{cm}^{2}\right)$, porosity ratio $17.06 \%$

$\mathrm{P} / \mathrm{M}$ compacting pressure $588 \mathrm{MPa}\left(6 \mathrm{ton} / \mathrm{cm}^{2}\right)$, porosity ratio $11.78 \%$

$\mathrm{P} / \mathrm{M}$ compacting pressure $784 \mathrm{MPa}\left(8 \mathrm{ton} / \mathrm{cm}^{2}\right)$, porosity ratio $8.75 \%$

$\mathrm{mm}$ at different applied pressures of 392,588 , and 784 MPa. 1 mass $\%$ of ACRAWAX was mixed with the powder as a lubricant for compaction. After forming at the room temperature with different pressures, compressed specimens were dewaxed in air at $673 \mathrm{~K}$ for $3.6 \mathrm{ks}$ and subsequently sintered in vacuum at $1473 \mathrm{~K}$ for $3.6 \mathrm{ks}$. These specimens are marked as $\mathrm{P} / \mathrm{M}$ specimens in the text and figures. The porosity ratios of $\mathrm{P} / \mathrm{M}$ specimens were measured according to JISZ2505 and they were 17.06, 11.78 and $8.75 \%$, respectively. For impedance measurement, reactive side of the specimen for the electrode was polished with a No. 2000 grit water-proofed abrasive paper followed by ultrasonic rinsing in acetone. The specimen electrode was coated with silicon rubber leaving an uncoated area of $1 \times 10^{-4} \mathrm{~m}^{2}$.

\section{$2.25 \% \mathrm{H}_{2} \mathrm{SO}_{4}$ boiling test}

$5 \% \mathrm{H}_{2} \mathrm{SO}_{4}$ boiling test was carried out according to JISG0591. Before being used for the experiment, specimens were subjected to ultrasonic rinsing in acetone and then weighed. The corrosion weight loss of specimens were measured after immersed in the boiling $5 \% \mathrm{H}_{2} \mathrm{SO}_{4}$ aqueous solution for given periods. Specimens were weighed using a precise balance with accuracy of $0.1 \mathrm{mg}$. 2.3 Measurement of electrochemical reactivation ratio

The schematic illustration for the electrochemical measurement is shown in Fig. 1. Specimens were polished with No. 2000 grit water-proofed abrasive paper followed by washing in alcohol and subsequent ultrasonic rinsing

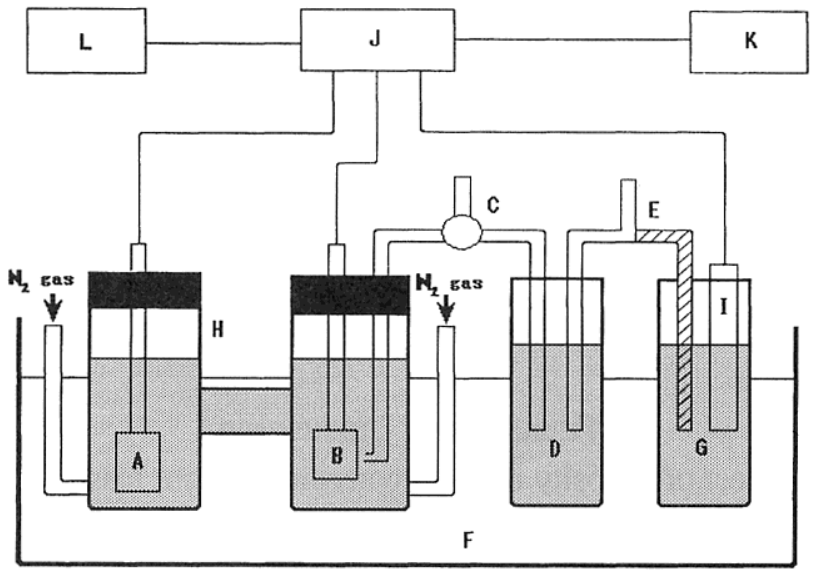

A: Counter electrode $(\mathbf{P t}) \quad$ B: Specimen C: Bridge D: Intermediate beaker E: Salt bridge

F: Water bath G: Saturated potassium chloride solution H: Electrochemicalcell I: Reference electrode J: Potentiostat K: Coulomb meter L: Computer

Fig.1 Experimental apparatus for electrochemical measurement.

in acetone. The test solution was composed of $0.5 \mathrm{kmol} / \mathrm{m}^{3}$ $\mathrm{H}_{2} \mathrm{SO}_{4}$ and $0.01 \mathrm{kmol} / \mathrm{m}^{3} \mathrm{KSCN}$ and kept at $303 \mathrm{~K}$ during test. Specimens were subjected to polarization in the positive direction from the natural electrode potential by computer controlled potential sweeping with potentiostat at the potential sweeping rate of $1.67 \mathrm{mV} / \mathrm{s}$. Immediately after the potential reached at $0.3 \mathrm{~V}(\mathrm{Ag} / \mathrm{AgCl} / 3.33 \mathrm{kmol} /$ 
$\mathrm{m}^{3} \mathrm{KCl}$ ), the reactivation was performed by the process in which the polarization toward the negative direction was carried out at the sweeping rate of $-1.67 \mathrm{mV} / \mathrm{s}$. The process was conducted to the terminal point at which the anodic current became 0 . Referring to the polarization curve thus obtained, the reactivation ratio was obtained according to JISGD580, and the method to obtain reactivation ratio from the anodic polarization curve was schematically illustrated in Fig. 2. The reactivation ratio was determined by the equation (1),

$$
\text { Reactivation ratio }=I_{r} / I_{a}
$$

where $I_{a}$ is the maximum anodic current density during polarization toward the positive direction and $I_{r}$ is the maximum anodic current density during polarization toward the negative direction.

\subsection{Immersion test}

The corrosion solutions, $2.5 \mathrm{kmol} / \mathrm{m}^{3} \mathrm{H}_{2} \mathrm{SO}_{4}+0,0.2,0.5$ and $1.0 \mathrm{kmol} / \mathrm{m}^{3} \mathrm{NaCl}$ were used in this experiment. Those corrosion solutions were adjusted by deionized water whose specific electric conductivity was less than $2.0 \times$ $10^{-5} \mathrm{~S} / \mathrm{m}$. The specimen was kept in the corrosion solution for $194.4 \mathrm{ks}$ at $303 \mathrm{~K}$, and then the corrosion weight loss against immersion time curves were obtained. In addition, the impedance measurement was conducted every $72 \mathrm{ks}$ in the same $2.5 \mathrm{kmol} / \mathrm{m}^{3} \mathrm{H}_{2} \mathrm{SO}_{4}$ and $0.2 \mathrm{kmol} / \mathrm{m}^{3} \mathrm{NaCl}$ solution and then the time dependence of polarization resistance was obtained.

\section{Results and Discussion}

3.1 Effect of porosity ratio on corrosion weight loss

The corrosion mass (weight) loss was investigated after

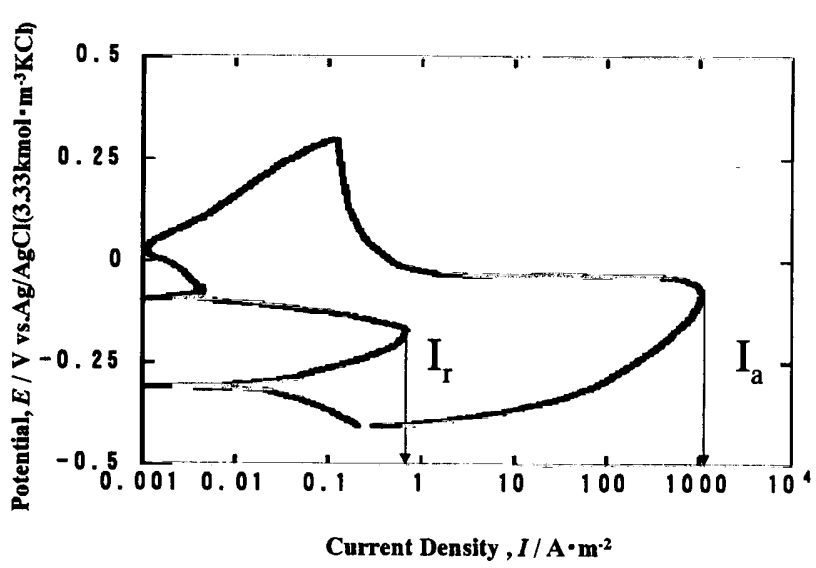

Fig.2 Method to obtain reactivation ratio from the anodic polarization curve. $I_{a}$ is the maximum anodic current density during positive polarization direction and $I_{r}$ is the maximum anodic current density during negative polarization direction. immersed in the boiled $5 \% \mathrm{H}_{2} \mathrm{SO}_{4}$ solution and the result was presented in Fig. 3. Corrosion mass loss was as small as $0.02 \mathrm{~kg} / \mathrm{m}^{2}$ for conventionally processed SUS 304 specimen, while it was more than $0.2 \mathrm{~kg} / \mathrm{m}^{2}$ for each sintered SUS304 specimen. In addition, the corrosion mass loss increased with increasing porosity ratio, which would suggest that porosity may be one of the factors to promote active dissolution in sintered materials.

\subsection{Effect of porosity ratio on reactivation ratio}

Fig. 4 shows the effect of porosity ratio on reactivation

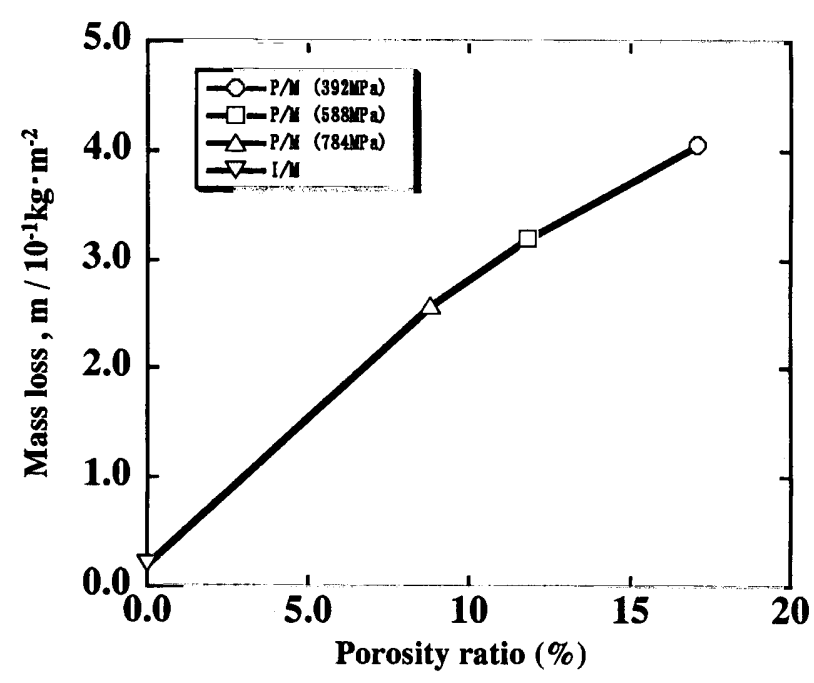

Fig.3 Effect of porosity ratio on mass loss for $I / M$ and $P / M$ SUS304 specimens after $5 \% \mathrm{H}_{2} \mathrm{SO}_{4}$ boiling test for $7.2 \mathrm{ks}$.

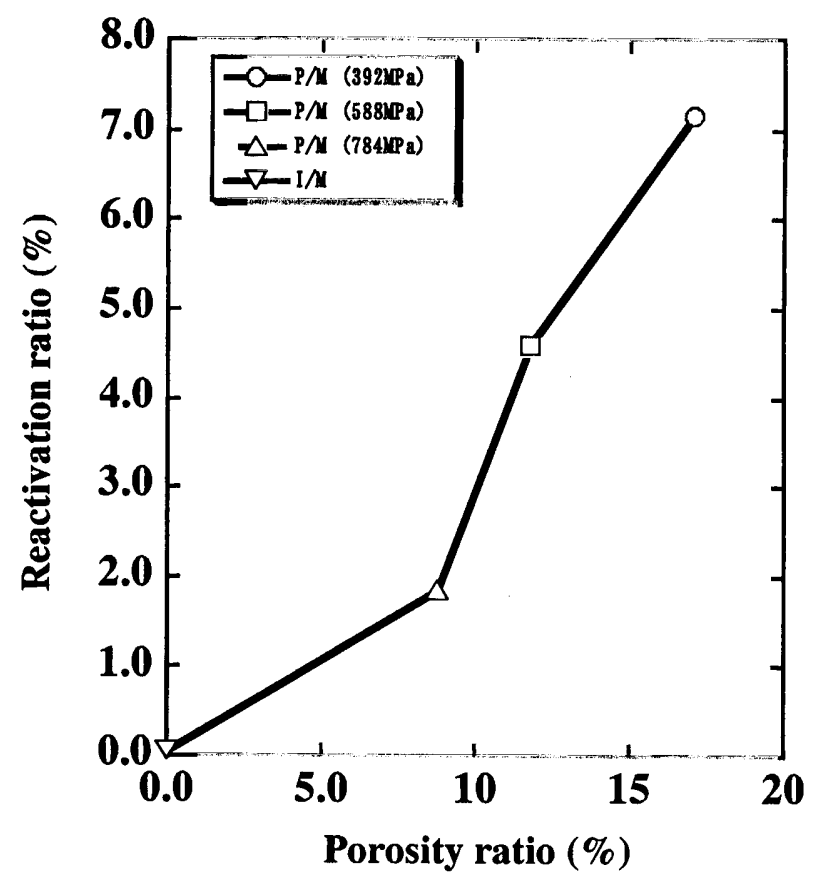

Fig.4 Effect of porosity ratio on reactivation ratio for $\mathrm{I} / \mathrm{M}$ and $\mathrm{P} / \mathrm{M}$ SUS304 specimens. Solution: $0.5 \mathrm{kmol} \cdot \mathrm{m}^{-3} \mathrm{H}_{2} \mathrm{SO}_{4}+0.01$ $\mathrm{kmol} \cdot \mathrm{m}^{-3} \mathrm{KSCN}$. Temperature: $303 \mathrm{~K}$. 
ratio for SUS304 stainless steels. Reactivation ratio for conventionally processed SUS304 specimen was as small as $0.06 \%$, while that for sintered SUS304 specimen was higher than $2 \%$ in any specimens. It is also observed that reactivation ratio rises almost linearly with the increase of porosity ratio. Concerning the results, it would be considered that pores may act on sintered SUS304 specimen surface to initiate passivation film which easily reactivates.

\subsection{Effect of $\mathrm{NaCl}$ concentration on mass loss}

Fig. 5 shows the effect of $\mathrm{NaCl}$ concentration on mass loss for specimens in the testing solutions, $2.5 \mathrm{kmol} / \mathrm{m}^{3}$ $\mathrm{H}_{2} \mathrm{SO}_{4}+0,0.2,0.5$ and $1.0 \mathrm{kmol} / \mathrm{m}^{3} \mathrm{NaCl}$, for $72 \mathrm{ks}$. For the I/M SUS304 specimen, mass loss was about $1.76 \times 10^{-1}$ $\mathrm{kg} / \mathrm{m}^{2}$ in the $\mathrm{H}_{2} \mathrm{SO}_{4}$ single solution, while almost no mass loss was observed in each solution with $\mathrm{NaCl}$ of $0.2,0.5$ and $1.0 \mathrm{kmol} / \mathrm{m}^{3}$. As for the P/M SUS304 specimens compressed at 392 and at $588 \mathrm{MPa}$, almost no mass loss was observed in the $\mathrm{H}_{2} \mathrm{SO}_{4}$ single solution. However, in the solution with $0.2 \mathrm{kmol} / \mathrm{m}^{3} \mathrm{NaCl}$ addition, both specimens showed the increment of mass loss, i.e. it was about $3.8 \times 10^{-1} \mathrm{~kg} / \mathrm{m}^{2}$ for the $\mathrm{P} / \mathrm{M}$ specimen compressed at $392 \mathrm{MPa}$ and $2.6 \times 10^{-1} \mathrm{~kg} / \mathrm{m}^{2}$ for the sintered specimen compressed at $588 \mathrm{MPa}$, respectively. In the higher concentration region than $0.2 \mathrm{kmol} / \mathrm{m}^{3} \mathrm{NaCl}$ the mass loss for P/M specimens compressed at 392 and $588 \mathrm{MPa}$

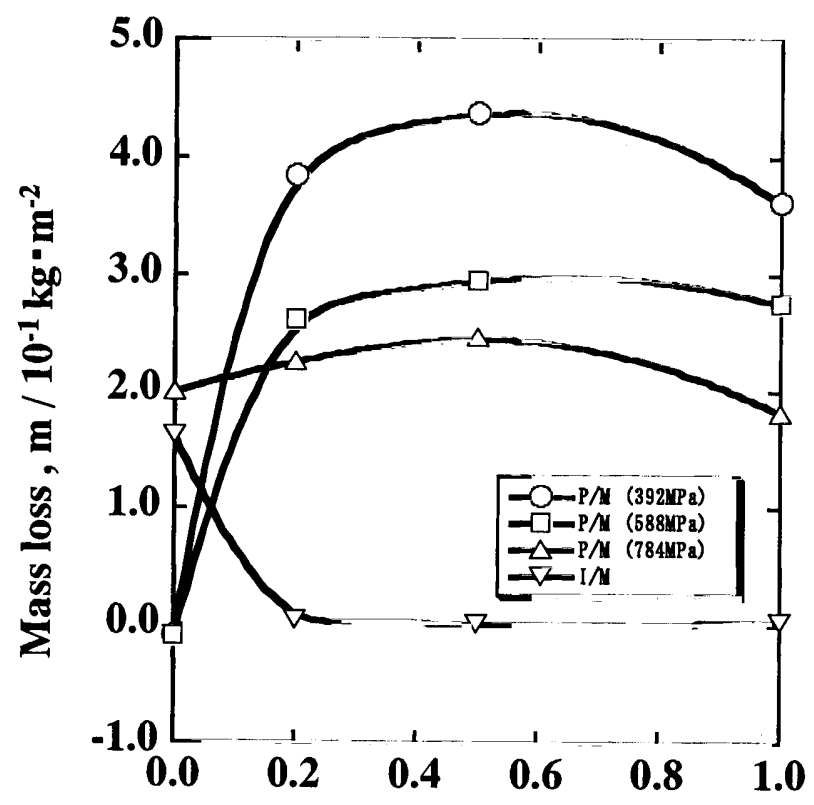

\section{$\mathrm{NaCl}$ concentration,$c / \mathrm{kmol}^{\cdot} \mathrm{m}^{-3}$}

Fig.5 Effect of $\mathrm{NaCl}$ concentration on mass loss for $\mathrm{I} / \mathrm{M}$ and $\mathrm{P} / \mathrm{M}$ SUS304 specimens. Solution: $2.5 \mathrm{kmol} \cdot \mathrm{m}^{-3} \mathrm{H}_{2} \mathrm{SO}_{4}+x \mathrm{kmol} \cdot \mathrm{m}^{-3}$ $\mathrm{NaCl}(x=0.0,0.2,0.5$ and 1.0).

Time: $72 \mathrm{ks}$. Temperature: $298 \mathrm{~K}$. increased a little with the rise of $\mathrm{NaCl}$ addition until it reached the maximum value at $0.5 \mathrm{kmol} / \mathrm{m}^{3} \mathrm{NaCl}$, above which it showed the tendency to decrease a little. As for the $\mathrm{P} / \mathrm{M}$ specimen compressed at $784 \mathrm{MPa}$, mass loss in the $\mathrm{H}_{2} \mathrm{SO}_{4}$ single solution was $2.0 \times 10^{-1} \mathrm{~kg} / \mathrm{m}^{2}$, which was much higher than that for the $\mathrm{P} / \mathrm{M}$ specimens compressed at 392 and $588 \mathrm{MPa}$. Further studies should be carried out in the future to clarify the cause of active dissolution behavior of the $\mathrm{P} / \mathrm{M}$ specimens compressed at $784 \mathrm{MPa}$ in the $\mathrm{H}_{2} \mathrm{SO}_{4}$ single solution compared to non-dissolution behavior of the $\mathrm{P} / \mathrm{M}$ specimens compressed at 392 and 588 $\mathrm{MPa}$. In the solution with $0.2 \mathrm{kmol} / \mathrm{m}^{3} \mathrm{NaCl}$ addition, mass loss for the P/M specimen compressed at $784 \mathrm{MPa}$ is a little more than that in the single solution, which differs from the result that the $\mathrm{P} / \mathrm{M}$ specimens compressed at 392 and $588 \mathrm{MPa}$ have much higher mass loss. Above $0.2 \mathrm{kmol} /$ $\mathrm{m}^{3} \mathrm{NaCl}$, mass loss kept a little increment with $\mathrm{NaCl}$ addition, and it reached the maximum value at $0.5 \mathrm{kmol} /$ $\mathrm{m}^{3} \mathrm{NaCl}$, which was as same phenomena as that observed in the P/M specimen compressed at 392 and $588 \mathrm{MPa}$. Considering the result, it is confirmed that in the solution with $\mathrm{NaCl}$ addition, mass loss of the $\mathrm{I} / \mathrm{M}$ specimens are well decreased with increasing amount of $\mathrm{NaCl}$, while that for the $\mathrm{P} / \mathrm{M}$ specimens with higher porosity ratio compressed at lower pressures is increased. Judging from the result, it is suggested that in the solution of $\mathrm{H}_{2} \mathrm{SO}_{4}$ with $\mathrm{NaCl}$ addition, porosity enhances mass loss for the P/M specimens. Asawa ${ }^{5-8)}$ has reported that $\mathrm{NaCl}$ addition works either as inhibitor or activator in the concentrated $\mathrm{H}_{2} \mathrm{SO}_{4}$ solution according to the added amount of $\mathrm{NaCl}$. Therefore, it would be considered that a little $\mathrm{NaCl}$ addition has played the role of an activator for the P/M specimen, while it has worked as an inhibitor against the I/M specimen.

3.4 Effect of reaction time on mass loss

For the purpose of clarifying corrosion behavior, mass losses for the $\mathrm{P} / \mathrm{M}$ and $\mathrm{I} / \mathrm{M}$ specimens are investigated in regard to reaction time, and the result is shown in Fig. 6. All of the P/M specimens showed the almost linear increment of corrosion mass loss against reaction time and the specimens with higher porosity ratio showed more mass loss, while the I/M specimen showed evidently much less mass loss than any other P/M specimens. It would by concluded that the $\mathrm{I} / \mathrm{M}$ specimen is more resistant to corrosion than the $\mathrm{P} / \mathrm{M}$ specimen. And from the result that the $\mathrm{P} / \mathrm{M}$ specimens with higher porosity ratio show more loss, it is considered that pores would affect mass loss for $\mathrm{P} / \mathrm{M}$ specimens. In addition, it is obvious that the time dependences of mass loss for the $\mathrm{P} / \mathrm{M}$ specimens are 


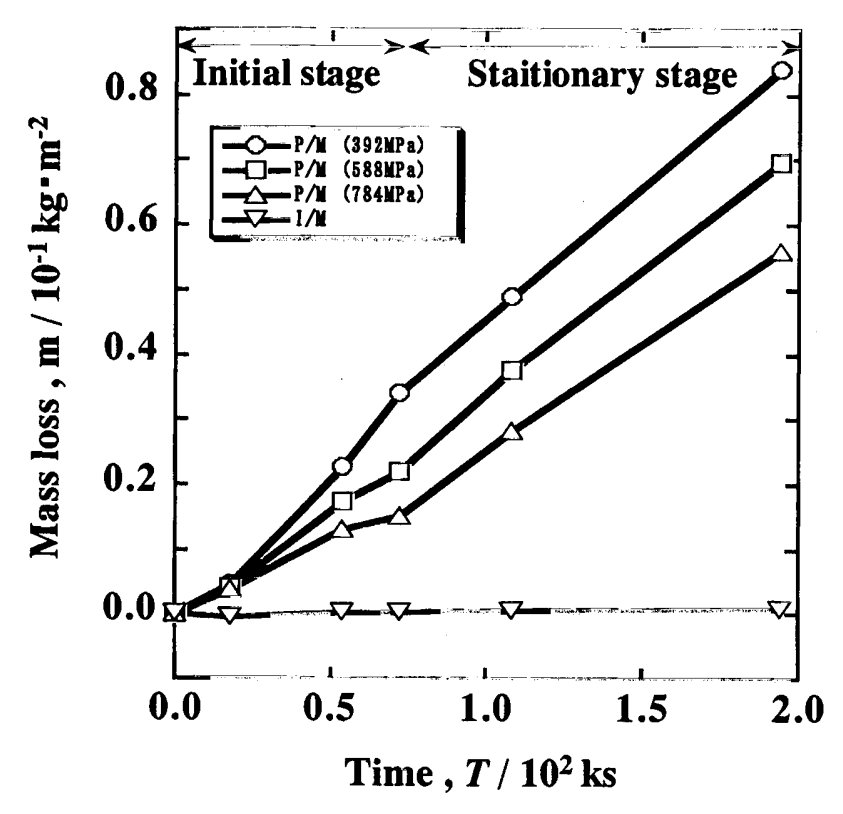

Fig.6 Effect of reaction time on mass loss for $\mathrm{I} / \mathrm{M}$ and $\mathrm{P} / \mathrm{M}$ SUS304 specimens. Solution: $2.5 \mathrm{kmol} \cdot \mathrm{m}^{-3} \mathrm{H}_{2} \mathrm{SO}_{4}+0.2$ $\mathrm{kmol} \cdot \mathrm{m}^{-3} \mathrm{NaCl}$. Time: $194.4 \mathrm{ks}$. Temperature: $298 \mathrm{~K}$.

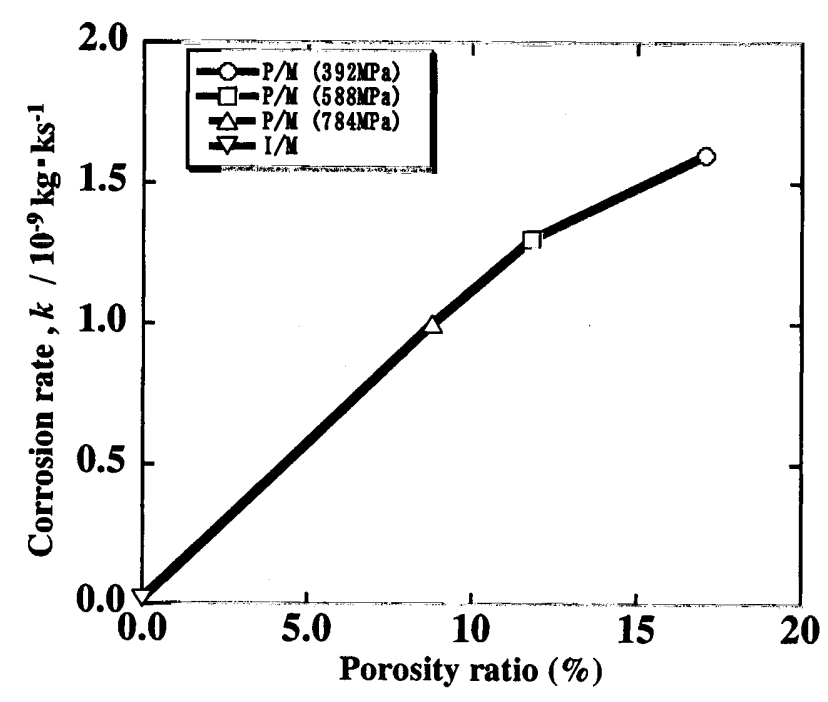

Fig.7 Effect of porosity ratio on the average corrosion rate for $\mathrm{I} / \mathrm{M}$ and P/M SUS304 specimens obtained from 0 to $194.4 \mathrm{ks}$. Solution: $2.5 \mathrm{kmol} \cdot \mathrm{m}^{-3} \mathrm{H}_{2} \mathrm{SO}_{4}+0.2 \mathrm{kmol} \cdot \mathrm{m}^{-3} \mathrm{NaCl}$. Temperature: $298 \mathrm{~K}$.

divided into two regions as shown in Fig. 6, i.e. the first one is reviewed as initial stage from 0 to $72 \mathrm{ks}$ in which the mass loss shows the increase with different slopes according to the compressing pressures, and the second one is the stationary stage from 72 to $194.4 \mathrm{ks}$ in which the mass loss for all $\mathrm{P} / \mathrm{M}$ specimens show the increase with almost same slope. Fig. 7 shows the effect of porosity ratio on apparent corrosion rate, $\mathrm{K}$, throughout the testing period from 0 to $194.4 \mathrm{ks}$. For the case of $\mathrm{I} / \mathrm{M}$ specimens,

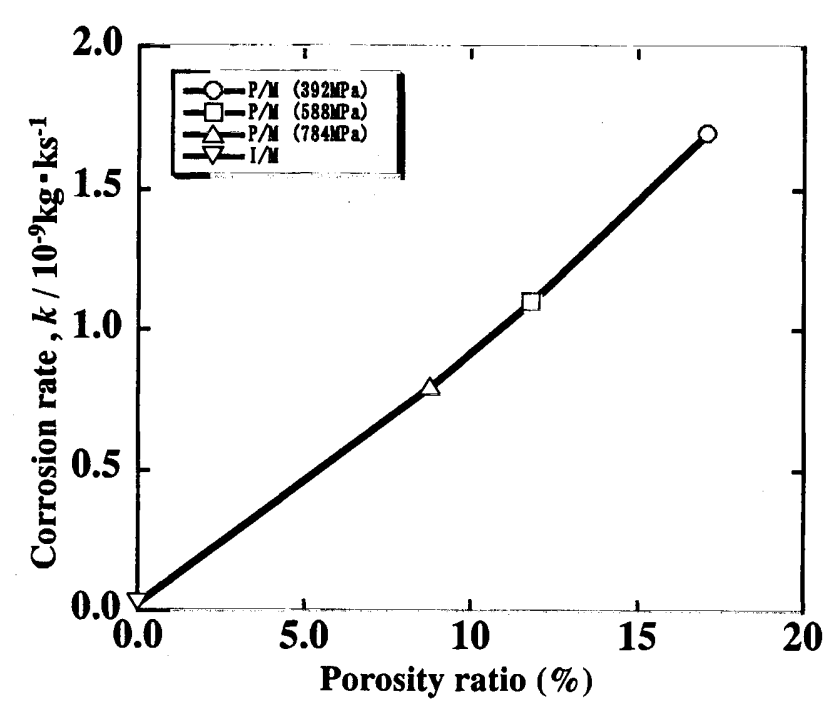

Fig.8 Effect of porosity ratio on corrosion rate for $\mathrm{I} / \mathrm{M}$ and $\mathrm{P} / \mathrm{M}$ SUS304 specimens during initial stage (from 0 to $72 \mathrm{ks}$ ).

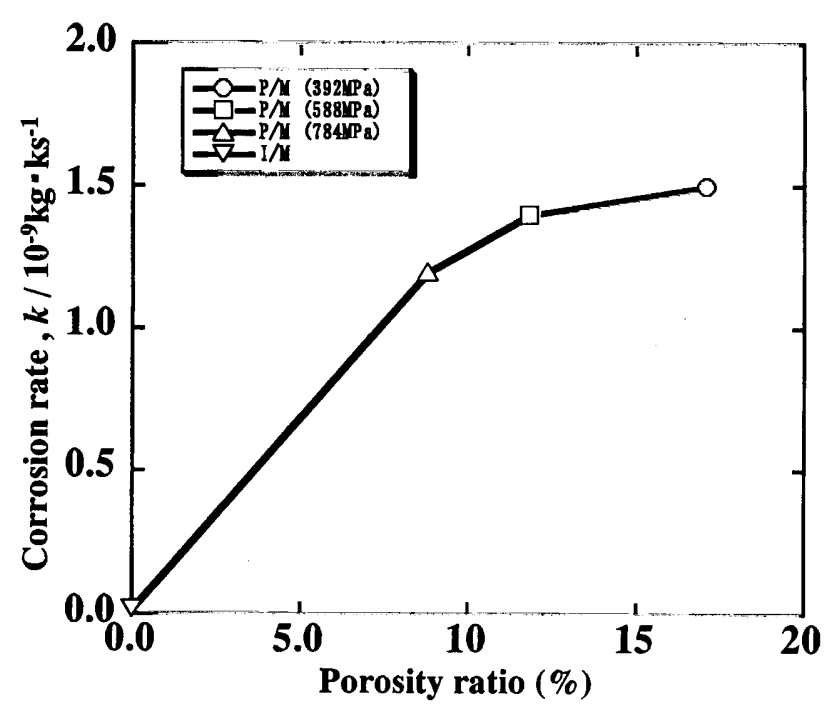

Fig.9 Effect of porosity ratio on corrosion rate for $\mathrm{I} / \mathrm{M}$ and $\mathrm{P} / \mathrm{M}$ SUS304 specimens during stationary stage (from 72 to 194.4 $\mathrm{ks})$.

porosity ratio was presumed to be $0 \%$ since they have no porosity resulted from production process. The corrosion rate constant increases when porosity increase, which would conclude that average corrosion rate almost primarily corresponds to porosity ratio throughout the testing period. Fig. 8 shows the effect of porosity ratio on the corrosion rate for the specimens during the initial stage from 0 to $72 \mathrm{ks}$, where the corrosion rate changes from $0.75 \times 10^{-9} \mathrm{~kg} / \mathrm{ks}$ for the specimen whose porosity ratio is $9.0 \%$ to $1.75 \times 10^{-9} \mathrm{~kg} / \mathrm{ks}$ for the specimen whose porosity ratio is $17.5 \%$. Fig. 9 shows the effect of porosity ratio on the corrosion rate for the $\mathrm{P} / \mathrm{M}$ specimens during stationary 
stage from 72 to $194.4 \mathrm{ks}$, where the corrosion rate changes from $1.20 \times 10^{-9} \mathrm{~kg} / \mathrm{ks}$ for the specimen whose porosity ratio is $9.0 \%$ to $1.50 \times 10^{-9} \mathrm{~kg} / \mathrm{ks}$ for the specimen whose porosity ratio is $17.5 \%$. Reviewing Fig. 8 and Fig. 9, it is considered that the corrosion rate is affected strongly by porosity ratio and primarily in the initial stage and that it is affected weakly in the stationary stage. Therefore, it would be concluded that the pores in $\mathrm{P} / \mathrm{M}$ specimens have main effect to determine corrosion rate almost unequivocally in the initial stage from 0 to $72 \mathrm{ks}$. However, more accurate investigation should be taken in the future to clarify this phenomena.

3.5 Effect of reaction time on resistance of charge transfer

Fig. 10 shows the charge transfer resistance, Rct, versus reaction time for the $\mathrm{P} / \mathrm{M}$ specimens obtained by the impedance measurement. Since Rct represents resistance against dissolution, high value of Rct indicates high dissolution resistance, i.e. high corrosion resistance. At $72 \mathrm{ks}$, Rct is highest in the P/M specimen compressed at $784 \mathrm{MPa}$, while it is lowest in the P/M specimen compressed at $392 \mathrm{MPa}$. In the longer region than $144 \mathrm{ks}$, all of the three $\mathrm{P} / \mathrm{M}$ specimens show the almost constant Rct value of $200 \Omega$. These Rct behavior well correspond to the time dependence curves of mass loss in Fig. 6, i.e. until $72 \mathrm{ks}$, the least mass loss is observed in the specimen compressed at $784 \mathrm{MPa}$, while most mass loss is obtained in the specimen compressed at $392 \mathrm{MPa}$, and in the longer region than $144 \mathrm{ks}$, all of the P/M specimens show almost similar increasing rate of mass loss irrespective of compacting pressures. Rct of I/M specimen was also measured and it's value was $3200 \Omega$. These results also correspond to the time dependence curves of mass loss in Fig. 6. Judging from the above mentioned, it would be suggested that the impedance method is one of the good ways to evaluate the corrosion behavior of the sintered materials.

\section{Summary}

In this study, the dissolution behavior of the sintered SUS304 stainless steel in the aqueous solution composed of $\mathrm{H}_{2} \mathrm{SO}_{4}$ and $\mathrm{NaCl}$ was examined compared with that of the conventionally processed SUS304 stainless steel. The main results obtained are as follows.

(1) The corrosion mass loss of the P/M SUS304 specimen was much larger than that of the I/M SUS304 specimen. In addition, the corrosion mass loss of the P/M SUS304 specimen increased with increasing porosity ratio.

(2) The reactivation ratio for the P/M SUS304 specimen was higher than the I/M SUS304 specimen, and it increased almost linearly with increasing porosity ratio.

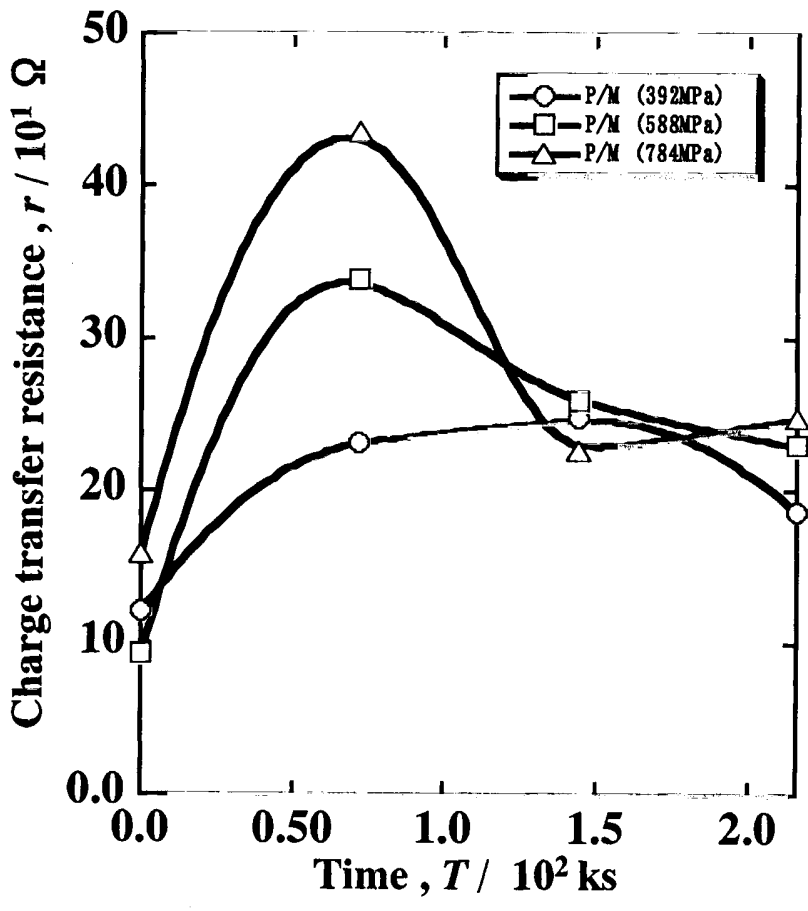

Fig.10 Effect of reaction time on charge transfer resistance for I/M and $\mathrm{P} / \mathrm{M}$ SUS 304 specimens. Solution: $0.5 \mathrm{kmol} \cdot \mathrm{m}^{-3}$ $\mathrm{H}_{2} \mathrm{SO}_{4}$. Temperature: $298 \mathrm{~K}$.

(3) Mass loss of the I/M specimen was decreased with increasing amount of $\mathrm{NaCl}$. On the other hand, the mass loss of the $\mathrm{P} / \mathrm{M}$ specimens with higher porosity ratio was increased with increasing amount of $\mathrm{NaCl}$.

(4) All of the P/M specimens showed the almost linear increment of corrosion mass loss against reaction time and the specimen with higher porosity ratio showed more mass loss, while the I/M specimen showed evidently much less mass loss than any $\mathrm{P} / \mathrm{M}$ specimens.

(5) In the case of $72 \mathrm{ks}$ of reaction time, Rct is highest in the $\mathrm{P} / \mathrm{M}$ specimen compressed at $784 \mathrm{MPa}$, while it is lowest in the P/M specimen compressed at $392 \mathrm{MPa}$. In the longer region than $144 \mathrm{ks}$, all of the three $\mathrm{P} / \mathrm{M}$ specimens show the almost constant Rct value of $200 \Omega$. These Rct behavior well correspond to the time dependence curves of mass loss.

\section{References}

1) S.Sunada, H.Maesato, Y.Yokoi, H.Notoya, S.Sanuki and K.Arai: "Effect of Deformation-Induced Martensite on Pitting Corrosion", J. Japan Inst. Metals, 54(1990) 1078-1086.

2) S.Sunada, N.Nakamura, H.Kawase, H.Notoya, S.Sanuki and K.Arai: "Effect of Deformation-Induced Martensite on the General Corrosion of SUS304 
Stainless Steel in $\mathrm{H}_{2} \mathrm{SO}_{4}-\mathrm{NaCl}$ Solution", J. Japan Inst. Metals, 55(1991)660-666.

3) S.Sunada, N.Nakamura, T.Mae, H.Notoya, S.Sanuki and K.Arai: J. Japan Inst. Metals, 57(1993)1047-1053.

4) S.Sunada, K.Majima, Y.Miyazaki and T.Hasegawa: "Evaluation of Pitting Corrosion Behavior of Sintered SUS444 Stainless Steel in $\mathrm{MgCl}_{2}$ Solution", J. Jpn. Soc. Powder Powder Metallurgy, 51 (2004)451-457.

5) M.Asawa: "Stress Corrosion Cracking of 18-8 Austenitic Stainless Steel in Sulfuric Acid Containing Sodium
Chloride", J. Japan Inst. Metals, 44(1970)871-877.

6) M.Asawa: "Stress Corrosion Cracking of 304 Stainless Steel in $\mathrm{H}_{2} \mathrm{SO}_{4}-\mathrm{NaBr}$ Aqueous Solution", J. Japan Inst. Metals, 44(1980)949-954.

7) M.Asawa: "Stress Corrosion Cracking of 304 Stainless Steel in $\mathrm{H}_{2} \mathrm{SO}_{4}-\mathrm{NaI}$ Aqueous Solution", J. Japan Inst. Metals, 44(1980)955-959.

8) M.Asawa: "Stress Corrosion Cracking of 304 Stainless Steel in $\mathrm{H}_{2} \mathrm{SO}_{4}-\mathrm{NaF}$ Aqueous Solution", J. Japan Inst. Metals, 44(1980)1194-1199. 